2. Kolthoff, I. M., Furman, N. H.: Potentiometric titrations, 2nd Ed., p. 159. New York: John Wiley 1931.

3. LaI, S., Christian, G. D.: Anal. Chem. 43, 410 (1971).

Dr. S. Lal

Department of Chemistry, University of Kentucky Lexington, Ky. 40506, U.S.A.

\section{Determination of Tungsten with a Permselective Membrane Electrode}

Bestimmung von Wolfram

mit einer permselektiven Membranelektrode

Sudarghan Lad

Department of Chemistry, University of Kentucky, U.S.A.

Received April 15, 1971

Smith and Bradbury [3], originally, reported the preparation of silver tungstate, a pale yellow precipitate, obtained by intermixing solutions of sodium tungstate and siver nitrate. The salt, $\mathrm{Ag}_{2} \mathrm{WO}_{4}$, is sparingly soluble in water, soluble in ammonia, nitric acid and is decomposed by heat and by treatment with several other reagents. Hence, the method did not gain acclaim as a suitable gravimetric method for the determination of tungsten. Recently, Shivahare [2] described the potentiometric determination of tungsten as $\mathrm{Ag}_{2} \mathrm{WO}_{4}$ using a silver wire as the indicator electrode.

The present communication embodies the potentiometric study of the silver nitrate-sodium tungstate reaction with the aid of a permselective membrane. The plastic membrane, impregnated with dithizone was used as the indicator electrode. Though the response of the membrane toward silver was nonNernstian, yet it monitored the relative changes of $\mathrm{Ag}^{+}$ions accurately.

Details of the electrode construction are described elsewhere [1]. All the chemicals used were reagent grade and their solutions were prepared in deionized distilled water. $25 \mathrm{ml}$ of silver nitrate solution were taken every time in a $50 \mathrm{ml}$ beaker and standard sodium tungstate solution was added from the microburette. With the addition of sodium tungstate, the e.m.f. increased to a certain limit and then fell sharply yielding very small changes after the end point. An average of six determinations yielded $23.16 \mathrm{mg}$ of $W$ when $22.98 \mathrm{mg}$ of $\mathrm{W}$ were originally present.

Titrations in the reverse order could not give reproducible results as on the addition of a few drops of silver nitrate solution, the e.m.f. values tremendously changed from negative to high positive values. Titrations in presence of $25 \%$ dioxane and $25 \%$ ethanol did not give sharp inflection points. Titrations in presence of sodium acetate, ammonium hydroxide and adjusting $\mathrm{pH}$ to 7 were not successful presumably due to diverse anions and cations present in the solution.

Acknowledgement. The author wishes to thank Dr. G. D. Christian for helpful discussions.

\section{References}

1. Lal, S., Christian, G. D.: Anal. Chem. 43, 410 (1971).

2. Shivahare, G. C.: Naturwissenschaften 52, 157 (1965); cf. Z. Anal. Chem. 230, 387 (1967).

3. Smith, E. F., Bradbury, R. H.: Chem. Ber. 24, 2930 (1891).

Dr. S. Lal

Department of Chemistry, University of Kentucky Lexington, Ky. 40506, U.S.A.

\section{Photometric Determination \\ of Vanadium(V), Titanium(IV), Manganese(II) and Iron(III) with N-Hydroxysuccinamic Acid (Di-Potassium Salt)}

Photometrische Bestimmung von Vanadium(V), Titan(IV), Mangan(II) und Eisen(III) mit dem Dikaliumsalz der N-Hydroxysuccinamidsäure

\section{S. P. Bhargava and N. C. Sogani}

Chem. Dept., University of Rajasthan, Jaipur (India)

Received March 24, 1971

Hydroxamic acids ( $\mathrm{R}-\mathrm{CO}-\mathrm{NH}-\mathrm{OH}$ ) have been widely investigated in the past 15 years for the determination of a number of metal ions. Bass and Yoe [1] have recently surveyed the reactions of 33 hydroxamic acids and $3 \mathrm{~N}$-substituted hydroxamic acids. We have examined a new hydroxamic acid, namely, di-potassium salt of N-hydroxysuccinamic acid ( $\mathrm{KOOC}-\mathrm{CH}_{2}-\mathrm{CH}_{2}-\mathrm{CO}-\mathrm{NH}-\mathrm{OK}$ ). It has the advantage of being water-soluble and giving water-soluble metal complexes, thus offering a suitable method for the photometric determination of metal ions like vanadium(V), titanium(IV), manganese(II) and iron(III).

Reactions with Metal Ions. The reagent develops an orange colour with $\mathrm{V}^{5+}(\mathrm{pH} 2.0-3.5)$ and $\mathrm{Fe}^{3+}$ ( $\mathrm{pH} 4.0-8.9$ ), intense yellow with $\mathrm{Ti}^{4+}$ ( $\mathrm{pH} 0.8$ to 